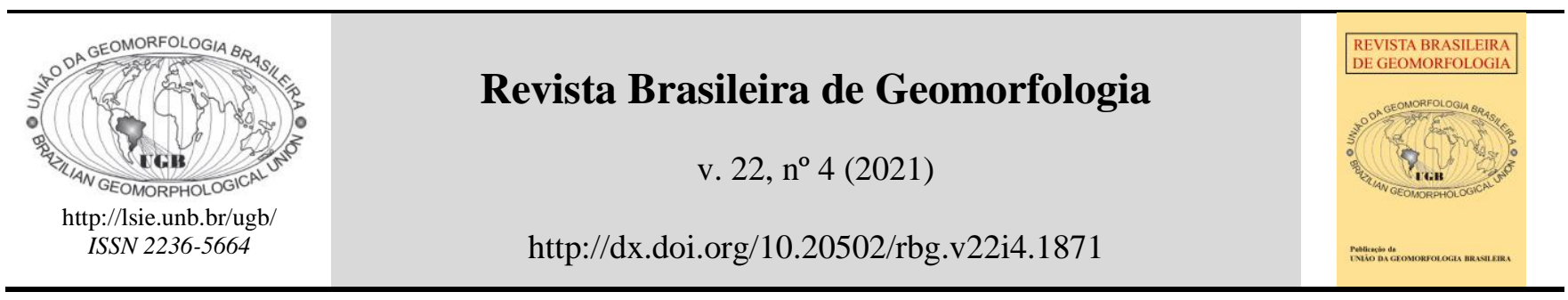

Nota técnica

\title{
Confecção de um simulador de chuvas móvel como ferramenta de disseminação do conhecimento Geomorfológico e preservação de ambientes
}

\section{Construction of a mobile rain simulator as a tool for the dissemination of geomorphological education and preservation of environments}

\section{Jefferson Gomes Confessor ${ }^{1}$, Lara Luíza Silva ${ }^{2}$ e Silvio Carlos Rodrigues ${ }^{3}$}

1 Universidade Federal de Uberlândia, Instituto de Geografia, Uberlândia, Brasil. jgconfessor01@gmail.com. ORCID: https://orcid.org/0000-0003-2337-4884

2 Universidade Federal de Uberlândia, Instituto de Geografia, Uberlândia, Brasil. laraluiza97@hotmail.com ORCID: https://orcid.org/0000-0002-4054-6820

3 Universidade Federal de Uberlândia, Instituto de Geografia, Uberlândia, Brasil. silgel@ufu.br. ORCID: https://orcid.org/0000-0002-5376-1773

Recebido: 27/02/2020; Aceito: 05/04/2021; Publicado: 01/10/2021

Resumo: Simuladores de chuvas são utilizados há tempos em diferentes configurações e propostas, normalmente ligados à compreensão da dinâmica da água. A degradação dos ambientes pela erosão hídrica resulta em diferentes passivos bem conhecidos, que são potencializados pela falta de manejo adequado em ações antrópicas. O uso de simuladores de chuvas, aliado às parcelas experimentais de erosão, proporciona ambiente capaz de expor de forma controlada, dados relativos à dinâmica da água no solo, se tornando ferramenta importante para o aprendizado e disseminação do conhecimento sobre a temática erosiva. Este artigo objetiva promover a difusão do uso de um simulador de chuvas simples e portátil, concomitantemente à parcelas de erosão, ambos de fácil mobilidade, expondo as bases necessárias para sua confecção e utilização em práticas voltadas à temática ambiental, a serem usados em escolas, feiras, congressos e demais lugares em que o tema se torne pertinente, contribuindo para disseminação do conhecimento geomorfológico e preservação de ambientes.

Palavras-chave: Simulador de chuva; Geomorfologia; Erosão

\begin{abstract}
Rain simulators have been used for a long time, presenting different configurations and proposals, usually linked to the understanding of water dynamics. The degradation of environments by water erosion results in different liabilities already known, which are enhanced by the lack of adequate management in anthropic actions. The use of rain simulators, combined with experimental erosion plots, provides an environment capable of exposing data related to the dynamics of water in the soil in a controlled manner, becoming a tool of great importance in the process of learning and disseminating knowledge about soil erosion. Thus, this article has the central objective of promoting the idealization of a simple and portable rainfall simulator, as well as erosion plots, both of which are easily mobile, exposing the necessary bases for its preparation and use in practices focused on the environmental theme, to be used in schools, fairs, congresses and other places whose theme is present, contributing to the dissemination of knowledge and preservation of environments.
\end{abstract}

Keywords: Rain Simulator; Geomorphology; Erosion 


\section{Introdução}

O uso de recursos naturais como solo e água, quando administrados de forma correta, pode minimizar os passivos existentes. Entretanto, o manejo inadequado ou sua inexistência pode interferir de forma negativa no meio, tornando o solo mais susceptível às forças naturais de degradação (FREITAS, MANZATTO, COUTINHO, 2001; CASTRO FILHO et al., 2002). Quando se trata de ambiente tropical, a erosão hídrica se efetiva como principal agente depauperador dos solos (BERTONI e LOMBARDI, 2010).

A perda de solo acarreta passivos in situ e áreas adjacentes, pois, ao se remover a camada superficial do solo, também se extraem nutrientes, matéria orgânica e organismos, todos de grande importância na sustentabilidade e qualidade dos ambientes. Os sedimentos são conduzidos e depositados em áreas a jusante, podendo ocasionar assoreamento e eutrofização de corpos d'água (DANIEL et al.,1994; BERTOL et al., 2007).

A degradação advinda de processos erosivos modifica dinâmicas pré-existentes no meio, alterando o balanço de entrada e saída de água no solo, que por consequência, altera a dinâmica hidrológica da área em seu entorno, interferindo na recarga de águas subterrâneas. Essas, por sua vez, influenciam a umidade superficial, que tem efeitos diretos na vegetação à qual dá suporte, além de alterar o volume e perenidade de exfiltração de água, que fornece abastecimento à córregos e rios (TRICART, 1977; OLIVEIRA JÚNIOR e DIAS, 2005; OLIVEIRA et al., 2009; PINESE JR, CRUZ e RODRIGUES, 2008).

Visando evitar possíveis danos em diferentes escalas, a possibilidade de prevenção do processo erosivo se mostra a melhor opção, uma vez que, depois de desencadeado, geram-se passivos por vezes irreparáveis (BENNETT, 1995). A efetivação do processo erosivo promove ônus de cunho ambiental, econômico e social, nos casos em que a recuperação ainda se mostra possível, normalmente seu reparo se mostra difícil, com custo alto e demandando longos períodos de tempo para reparação.

A educação ambiental surge nesse contexto como ferramenta de disseminação do conhecimento frente à problemática (CAPECHE, 2009), com capacidade de levar à tomada de consciência sobre a importância da manutenção da qualidade dos solos e do entendimento na compreensão sistemática na qual esse faz parte. Abordagens práticas são de grande relevância, visto que a observação empírica realizada pelo indivíduo sobre o fato acontecido possibilita reflexões a respeito de ações capazes de gerar determinadas consequências. Partindo desse princípio e correlacionando com a problemática erosiva, a exposição prática da gênese e consequências da erosão se mostra relevante, uma vez que permitirá observar os mecanismos de formação e os danos impostos por tal.

Simuladores de chuvas são desenvolvidos há tempos com o intuito de compreender a dinâmica erosiva (TOSSEL et al., 1987; OLIVEIRA, 1991; ALVES SOBRINHO, FERREIRA e PRUSKI, 2002; SPOHR et al., 2015; CONFESSOR e RODRIGUES, 2018; CARVALHO, CONFESSOR e RODRIGUES, 2021). São ferramentas capazes de serem incorporadas a métodos de ensino voltados à educação ambiental, na medida em que ilustram a formação de processos em pequenas escalas, sendo sua mobilidade ponto crucial para realização de deslocamentos para exibição junto ao público alvo.

Esse trabalho objetiva expor os materiais e métodos necessários para elaboração de um simulador de chuvas móvel, assim como parcelas de erosão capazes de conceber processos em pequena escala, permitindo visualizar a gênese de processos e expor a dinâmica da água no solo em diferentes ambientes cuja temática possa ser trabalhada, como em escolas, feiras e universidades.

\section{Materiais e Métodos}

Estudos com intuito de reproduzir chuvas artificiais devem se atentar para fatores que visam dar maior veracidade à simulação, de forma a considerar as condições naturais de chuva, como tamanho de gotas; 
distribuição homogênea da precipitação; altura de queda e sua velocidade terminal das gotas (MEYER e HARMON, 1979; LUK, ABRAHAMS e PARSONS, 1986).

A reprodução desses fatores possibilita a montagem de um simulador capaz de replicar eventos de forma similar aos ocorrentes na realidade. Entretanto, o uso de precipitações simuladas como instrumento para promover a educação ambiental não necessariamente depende de atender a todos os procedimentos de um simulador de chuvas científico, pois, nesse caso a identificação visual do processo é mais relevante.

Diversos estudos utilizaram equipamentos mais simples para replicar precipitações, como Capeche (2009), que empregou um simples regador. Porém, a utilização do simulador não desvaloriza equipamentos mais simples, que por vezes podem tornar a prática menos laboriosa, contudo, a presença do equipamento captura a atenção do público, por se tratar de uma ferramenta socialmente pouco disseminada. Partindo disso, o simulador pode estabelecer conexões com diferentes conteúdos, que possivelmente não seriam proporcionadas pela utilização de outra ferramenta. Além da possiblidade de exposição da prática em si e todo o processo a ela relacionada, seu uso também possibilita demonstrar as informações necessárias para produção de trabalhos científicos e o rigor que esses demandam.

\subsection{Simulador de chuvas}

O simulador apresentado nesse estudo se apresenta de fácil mobilidade e manejo. Inteiramente confeccionado em tubos de aço galvanizado de $19 \mathrm{~mm}$ de diâmetro, o equipamento possui as seguintes dimensões (Figura 1): Haste vertical de 2,5 metros de altura (A), em seu topo utiliza-se uma curva também de aço galvanizado para encaixe de outra haste (B) de $90 \mathrm{~cm}$, utilizada para prolongamento do jato de água, sendo conectada em sua extremidade o bico de pulverização (FullJet 1/2 HH-27WSQ) (C), capaz de reproduzir diversas situações de pluviosidade, sendo o fluxo de água regulado por uma válvula em sua base (D). Cabos de poliéster promovem a fixação (E) ligados a ganchos de ferro que podem estar inseridos no solo (F).

O funcionamento do equipamento se efetiva de forma simples, necessitando apenas do encaixe de uma mangueira na extremidade inferior, ligada a uma torneira; a pressão advinda da rede pública de água permite o funcionamento do equipamento, gerando a formação do fluxo de gotas sobre a superfície.

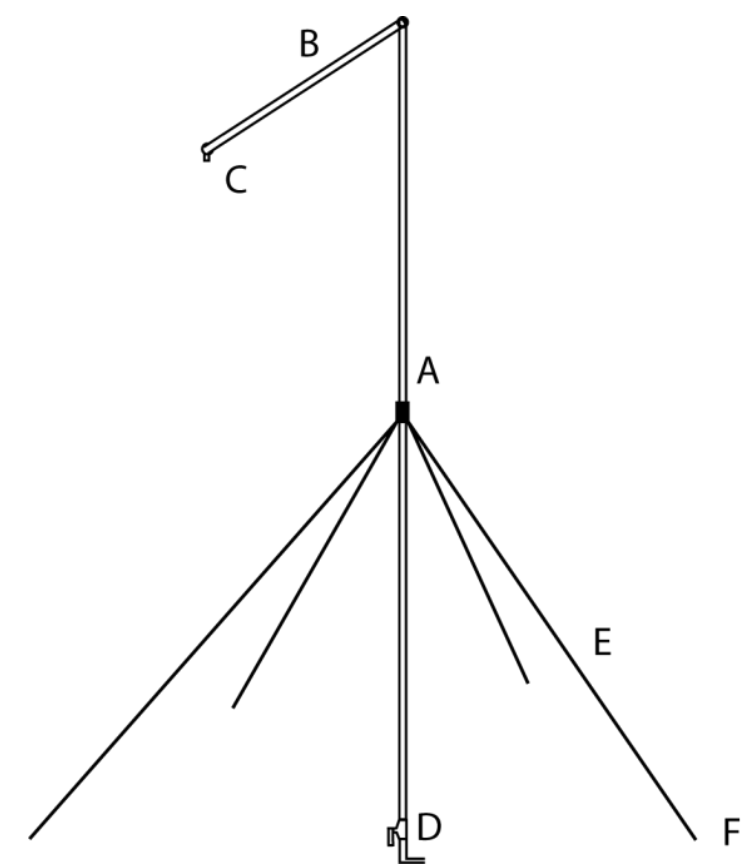

Figura 1. Simulador de chuvas simples e de fácil mobilidade. Desenvolvido em partes seccionáveis para facilitar seu transporte e uso em práticas ambientais locadas em diversos ambientes. Fonte: Autores. 
Por se tratar de um equipamento compacto e leve, sua utilização pode ser incorporada em diversos tipos de ambientes, e, por apresentar conexões rosqueáveis, apresenta montagem e desmontagem facilitada, ampliando sua capacidade de movimentação e manuseio, não necessitando de grandes espaços para seu armazenamento.

\subsection{Parcela de Erosão}

Posterior à construção do simulador de chuvas, necessita-se de um ambiente controlado para avaliação dos efeitos ocasionados pela ação da precipitação, com capacidade de expor informações de forma empírica e quantitativa dos resultados gerados entra a interação da precipitação, solo e sua cobertura. Para isto, parcelas de erosão se efetivam como excelentes instrumentos de análise, sendo utilizadas em trabalhos voltados à temática erosiva (THOMAZ e ANTONELI, 2008; PANACHUKI et al., 2011; CONFESSOR, 2019), pois as mesmas possuem medidas conhecidas, aprisionando e direcionando os fluxos superficiais e até subsuperficiais de água para recipientes externos, capazes de produzir informações sobre volumes de água e solo erodidos.

A variedade de modelos de parcelas existente reflete as necessidades de cada pesquisa. Para esse trabalho, optou-se pela elaboração de um modelo compacto e móvel, com possibilidade de transporte para realização de experimentos em diferentes localidades, apresentando baixo custo de produção.

O modelo escolhido aproxima-se do exposto por Capeche (2009), no qual um vasilhame acomoda a mistura de solo e seixos para criar um ambiente semelhante ao natural. A dinâmica dos fluxos e materiais pode ser compreendida na Figura 2, podendo haver alterações nos materiais por outros similares, que variam de acordo com as exigências de cada experimento, ressaltando-se que eventuais modificações produzirão dinâmicas internas diferentes.

A superfície de impacto das gotas precipitadas está representada pela camada (A), que pode apresentar diferentes tipos de materiais a critério de cada trabalho, como solo exposto, cobertura vegetal, ou determinados pavimentos urbanos (variando de acordo com as necessidades). Nas situações que exijam plantio, esse deve preceder o processo de simulação, permitindo que a vegetação cresça e se fixe na camada superior do solo da parcela.

A camada (B) representa o solo, cuja constituição também é flexível; podem ser utilizados diferentes tipos texturais, variando entre os muito arenosos aos muito argilosos. Para melhor dinâmica interna da água e visando produzir um ambiente com capacidade de infiltração e coleta dos fluxos escoados superficialmente e infiltrados, o solo adicionado na parcela deve ser destorroado, porém não por completo, conservando a presença de agregados, que permitem melhor estruturação ao acomodar-se nas parcelas.

Quando os teores de argila se apresentarem altos, é interessante misturar o solo com areia grossa, em proporção que facilite também a infiltração da água no perfil. Cabe ressaltar que a altura da camada A e B não devem ultrapassar o bico de saída superior D1, evitando obstruções de saída da água que escoa superficialmente. A camada (C), deve ser preenchida com material grosso (drenante), como cascalho ou brita, para permitir a coleta do fluxo de água infiltrada pela saída inferior; sendo assim, toda base da parcela deve ser preenchida com este material até ultrapassar o orifício inferior de saída (D2), evitando possíveis obstruções na saída do fluxo de água infiltrada no solo.

Após preenchida, deve-se adicionar água na parcela de forma gradual e lenta, para que o material em seu interior se acomode. $\mathrm{O}$ acomodamento reduzirá o volume dentro da parcela, sendo necessário em alguns casos a adição de mais solo, pois o nível da camada superior deve coincidir com a abertura superior de saída (D1), evitando empoçamentos ou obstruções. 
A inclinação da parcela é realizada por meio da elevação de sua lateral traseira, variando de acordo com o tamanho do componente (E), ficando a critério de cada pesquisa, sendo que, usualmente quando maior o gradiente, maiores volumes escoados superficialmente serão apreciados.

Os fluxos internos da parcela se dividem em três, a água excedente que não infiltra e escoa superficialmente (1); a água que está em processo de infiltração no solo (2) e, por fim, a água que infiltrou por completo a camada de solo, sendo conduzida até o ambiente de saída inferior por meio da percolação entre o material drenante (3).

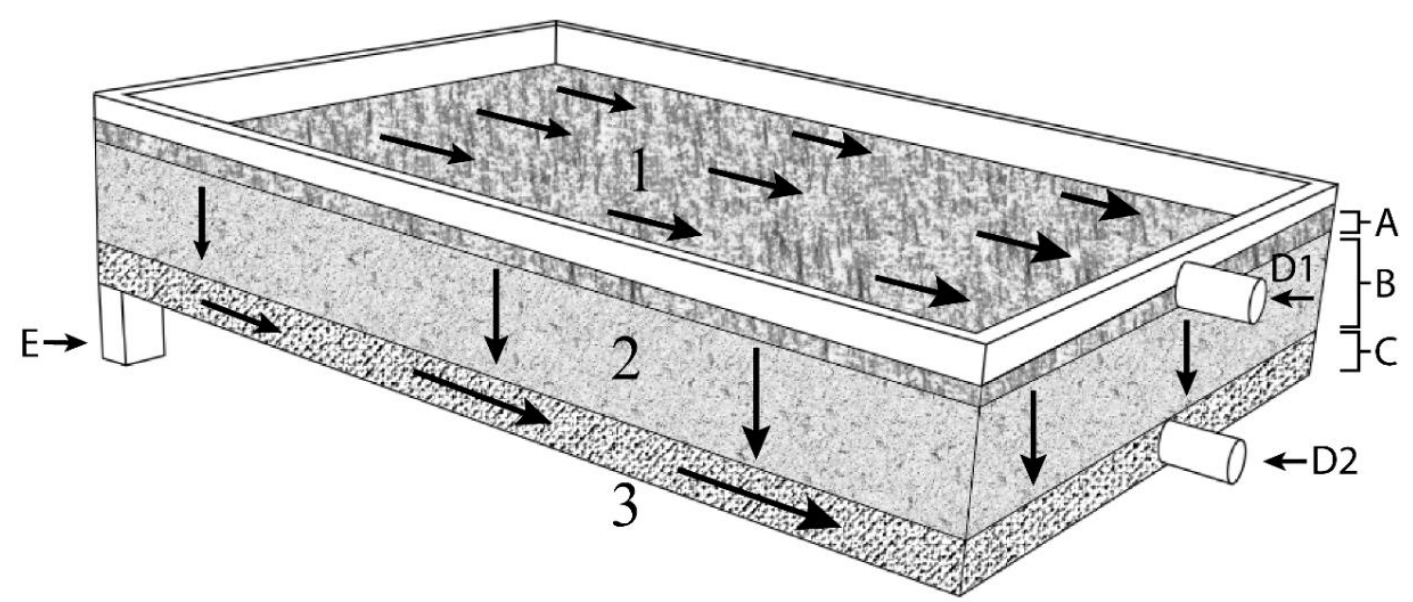

Figura 2. Modelo de parcela capaz de representar a dinâmica hídrica no solo, com possibilidade de variação em seus constituintes. Sendo representado o material superficial que recobre a parcela (A); Camada de solo (B); Camada de material drenante (C); Fluxos de água representados por setas e letras, sendo: Escoamento superficial (1), Água infiltrada no solo (2); Água infiltrada sendo conduzida ao bico de saída inferior (3); Bicos de saída, superior (D1), inferior (D2); Sobressalto para inclinação da parcela (E). Fonte: Autores.

O funcionamento das parcelas é bastante simples e se faz de forma análoga aos processos que podem ocorrer no meio natural. A modificação de um de seus componentes permite alterar a dinâmica do sistema fechado. Assim, a variação nos diferentes componentes de cada parcela possibilita representar uma gama ampla de situações encontradas nos ambientes naturais.

Para esse estudo, a parcela foi construída por meio do uso de um galão de plástico de 30 litros, o qual foi seccionado ao meio (Figura. 3A), oferecendo material suficiente para elaboração de duas parcelas por galão, com dimensões de 50 centímetros de altura, 30 centímetros de largura, 15 centímetros profundidade, totalizando um volume de $22.500 \mathrm{~cm}^{3}$, preenchidas conforme procedimentos anteriormente descritos. 


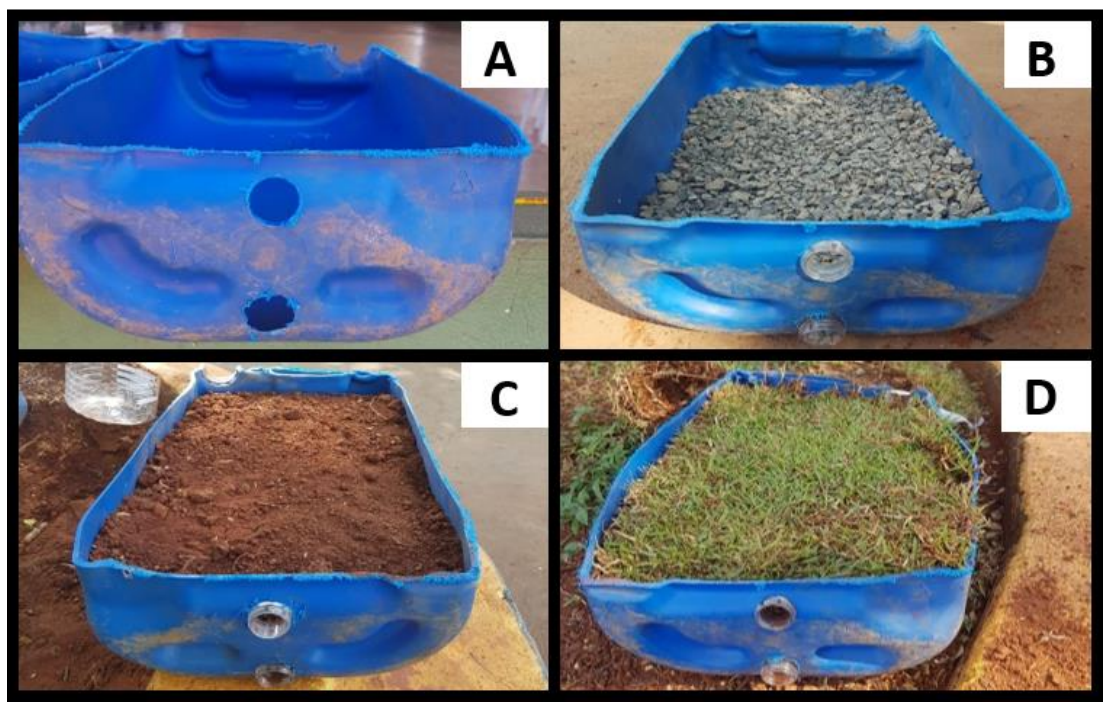

Figura 3. Parcelas de erosão confeccionadas a partir de um galão de $30 \mathrm{~L}$, seccionado em duas metades. Abertura de orifícios em duas profundidades para encaixe de bicos de garrafas PET (A); Preenchimento com material drenante sobre a superfície inferior da parcela até o cobrimento do bico de saída inferior (B); Preenchimento com solo destorroado até o nível do bico superior (C); Recobrimento do solo com tapete de grama (C). Fonte: Autores.

O modelo de simulador em questão exibe a possibilidade de uso simultâneo de até três parcelas como as descritas (Figura 4), às quais podem ser utilizadas com diferentes coberturas (a variar de acordo com cada estudo). A título de exemplo, uma das parcelas pode estar não vegetada, com solo exposto, outra estar totalmente recoberta por vegetação (como a grama do modelo da Figura 4), e por fim, outra impermeabilizada por cimento, visando contemplar pavimentos urbanos.

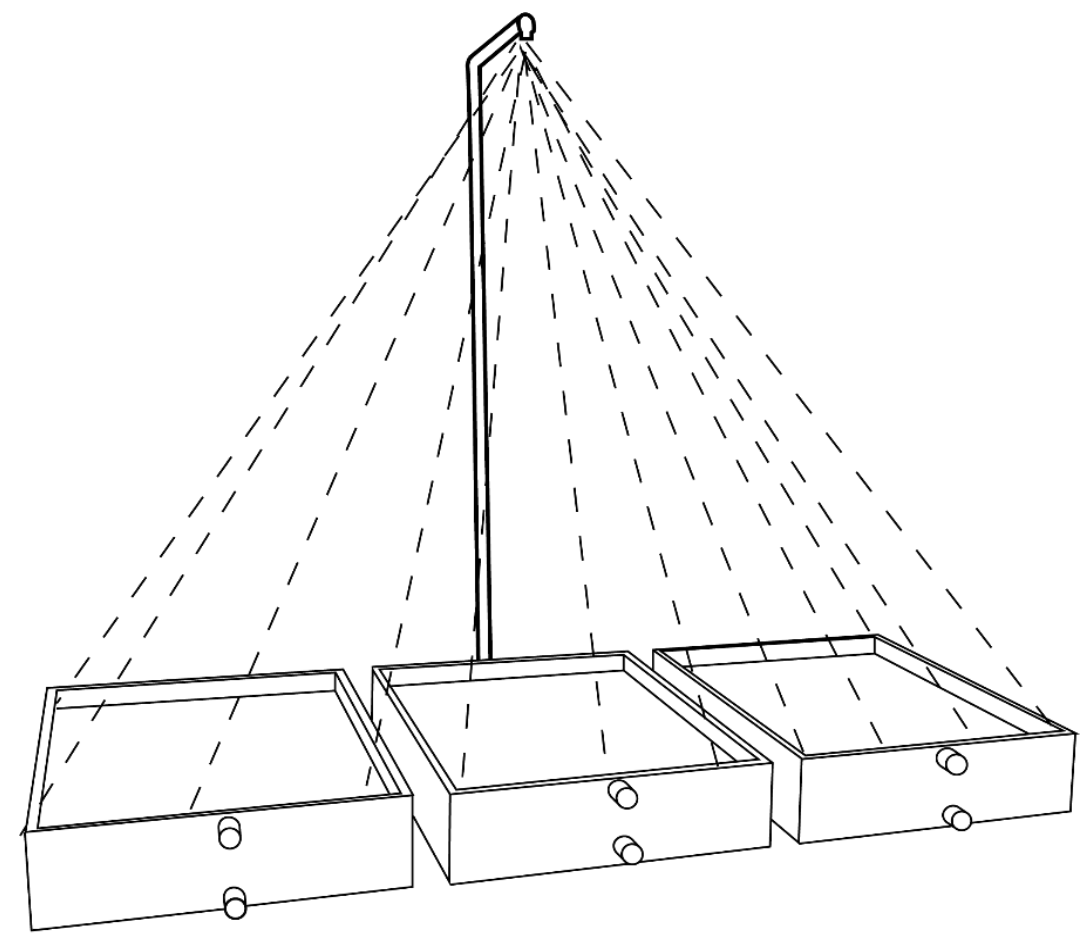

Figura 4. Parcelas de erosão inseridas sob simulador de chuvas, com intuito de produzir experimentos voltados ao processo de educação ambiental. Fonte: Autores. 
Para facilitar a acomodação dos recipientes de coleta dos fluxos, o posicionamento das parcelas sobre uma superfície elevada é ideal (como por exemplo uma mesa), com o cuidado de eliminar obstáculos que interceptem a precipitação destinada ao interior das parcelas.

\subsection{Recipientes de coleta}

A dinâmica da água pode ser mensurada pela visualização direta dos recipientes de coleta, os quais expõem dados referentes ao início do escoamento, tempo de infiltração, volumes escoados e infiltrados, assim como possibilitam estimar a quantidade de sedimentos erodidos de forma empírica no próprio local (Figura 5), por meio da observação da coloração da solução de água, proveniente da quantidade de material em suspensão, além da verificação da presença de material de fundo.
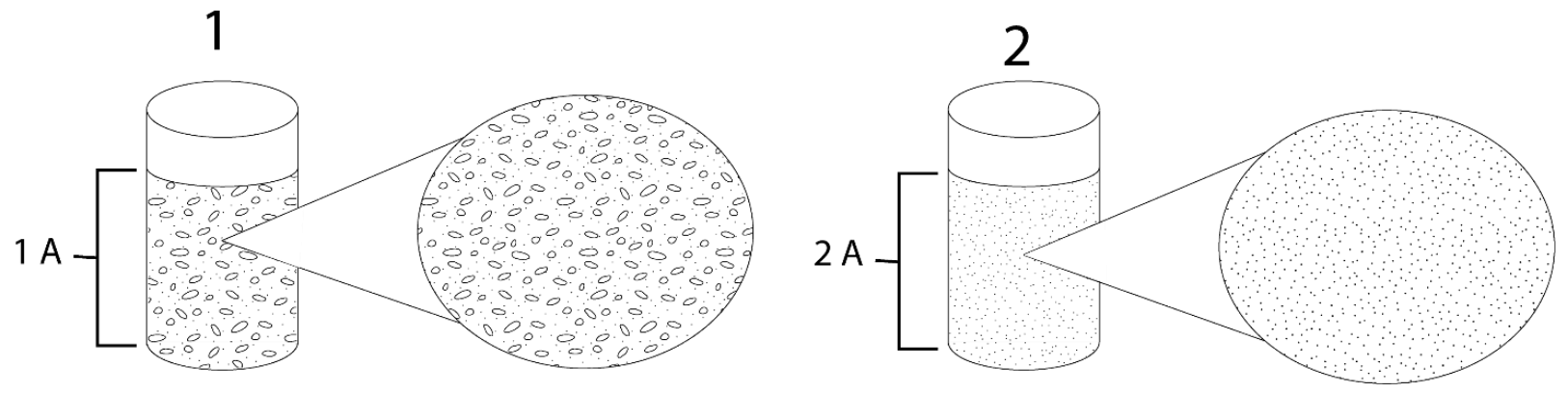

Figura 5. Recipientes de coleta; volumes de água coletada (1 e 2); quantidade de sedimentos em solução (1A e 2A). Fonte: Autores.

Essa facilidade em expor dados referentes a dinâmica hídrica na parcela, oferece oportunidade para emprego dessa ferramenta em diferentes localidades e níveis de ensino, dando oportunidade para expor dados visuais de ações exercidas nas alterações dos ambientes, possibilitando acompanhar os volumes de água escoada e infiltrada, assim como o tipo de material que os fluxos carreiam consigo, possibilitando correlacionar com situações reais.

\section{Considerações finais}

A utilização de um simulador de chuvas juntamente com parcelas de solo proporciona a realização de um estudo sistêmico, envolvendo diferentes tipos de agentes do meio físico. Permite ainda fazer conexões com diferentes conteúdos relacionados ao tema, como o ciclo da água, a distribuição dos solos e diferentes tipos de vegetação. Os experimentos podem ilustrar diversos aspectos: (a) a importância da erosão natural para rejuvenescimento dos solos; (b) de que forma a distribuição do material transportado pode beneficiar ou não áreas de aporte dos sedimentos gerados; (c) as formas pelas quais a relação homem-meio pode afetar a dinâmica, alterando ciclos pré-estabelecidos, acelerando o processo erosivo e ressaltando as consequências dos efeitos in situ e adjacências.

O modelo fornece as bases necessárias à compreensão da dinâmica hídrica no solo e no ambiente, abrindo espaço para abordagens mais amplas e interdisciplinares, como o cálculo da energia cinética das gotas de chuva (física), o efeito químico da água no solo (química), a necessidade da água para os seres vivos (biologia), o efeito do escoamento superficial em cidades, como os consequentes alagamentos (geografia), além de disseminar o rigor metodológico necessário para elaboração de um estudo científico.

A ferramenta de montagem e funcionamento simples, captura a atenção do público e possibilita o trabalho de diferentes tipos de conteúdo, integrando-se grupos de estudo provenientes de distintas disciplinas no ambiente 
escolar. Podendo gerar discussões em diversos níveis a partir de um único princípio, o simulador. Sendo uma única ferramenta capaz de expor, de forma didática e elucidativa, o funcionamento de sistemas complexos, integrando-se múltiplos objetos de estudo.

Conclui-se que simuladores de chuvas itinerantes podem ser aplicados em escolas, universidades, feiras e congressos, além da visitação em propriedades rurais. No processo de ensino, esses instrumentos permitem criar situações favoráveis à educação ambiental em diversos níveis, possibilitando a visualização de forma rápida de causas e consequências de determinadas ações no meio, promovendo ambiente para o repasse de informações e estimulando a conscientização ambiental.

Contribuições dos Autores: Este artigo se apresenta como produto do trabalho conjunto dos autores, sendo: Concepção ${ }^{1,2-3}$; metodologia' ${ }^{1-2}$; pesquisa ${ }^{1,2-3}$; recursos ${ }^{1,2-3}$; escrita do $\operatorname{artigo~}^{1-2}$; revisão ${ }^{1,2,3}$; supervisão ${ }^{3}$; aquisição de financiamento 1,2,3 divididos entre os participantes. Assim sendo, todos os autores leram e concordam com a versão publicada do manuscrito.

Financiamento: Esta pesquisa não recebeu nenhum financiamento externo.

Agradecimentos: Agradecimento a CAPES pela bolsa de Doutorado do primeiro autor e bolsa de Mestrado do segundo autor.

Conflito de Interesse: Os autores declaram não haver conflito de interesse.

\section{Referências}

1. ALVES SOBRINHO, T.; FERREIRA, P. A.; PRUSKI, F. F. Desenvolvimento de um infiltrômetro de aspersão portátil. Revista Brasileira de Engenharia Agrícola e Ambiental, v.6, n.2, p.337-344, 2002.DOI:https://doi.org/10.1590/S1415$\underline{43662002000200025}$

2. BENNETT, H.H. Elements of soil conservation. 2. ed. Tokyo: Kogakusha, p. 358. 1995.

3. BERTOL, I.; COGO, N.; SHICK, J.; GUDAGNIN, J.; AMARAL, A. Aspectos financeiros relacionados às perdas de nutrientes por erosão hídrica em diferentes sistemas de manejo do solo. Revista Brasileira de Ciência do Solo. v.31, n. 1, p. 133-142, 2007. DOI: https://doi.org/10.1590/S0100-06832007000100014

4. BERTONI, J.; LOMBARDI NETO, F. Conservação do solo. 7.ed. São Paulo, Ícone, p. 355, 2010.

5. CAPECHE, C. Confecção de um simulador de erosão portátil para fins de educação ambiental. Dados eletrônicos. - Rio de Janeiro: Embrapa Solos, 2009. 31 p. - (Embrapa Solos, Documento 116. ISSN 1517-2627)

6. CASTRO FILHO, C. COCHRANE, T.A. NORTON, L.D. CAVIGLIONE, J. H. JOHANSSON, L.P. Land degradation assesment: tools and techniques for measuring sediment load. In: INTERNATIONAL CONFERENCE ON LAND DEGRADATION AND MEETING OF THE IUSS SUBCOMMISSION C - SOIL AND WATER CONSERVATION, Rio de Janeiro: EMBRAPA Solos, 2002.

7. CARVALHO, F.; CONFESSOR, J.; RODRIGUES, S. Utilização de simulador de chuvas para determinação do valor CN e abstração inicial na cultura do café em ambiente de cerrado brasileiro. Revista Physis Terrae. v. 2 n. 2: Metodologias em Geomorfologia, 2021. DOI: https://doi.org/10.21814/physisterrae.3083

8. CONFESSOR, J. G. Avaliação de processos erosivos hídricos em diferentes usos agrícolas, utilizando simulador de chuvas no ambiente de Cerrado. Dissertação de mestrado, Universidade Federal de Uberlândia, Uberlândia-MG, (2019). DOI: http://dx.doi.org/10.14393/ufu.di.2019.606

9. CONFESSOR. J. G.; RODRIGUES, S. C. Método para calibração, validação e utilização de simuladores de chuvas aplicados a estudos hidrogeomorfológicos em parcelas de erosão. Rev. Bras. Geomorfologia. (Online), São Paulo, v.19, n.1, p.221229, 2018.DOI: http://dx.doi.org/10.20502/rbg.v19i1.1294

10. DANIEL, T.C; SHARPLEY, A. N.; WEDEPOBL, E. R; LEMUNYON J.L. Minimizing surface water eutrophication from agriculture by phosphorus management. J. Soil Water Conserv. USDA. V.49, ed. 2, p. 30-38, 1994. ISSN: 0022-4561

11. FREITAS, P. L. de; MANZATTO, C. V.; COUTINHO, H. L. C. A crise de energia e a degradação dos recursos naturais: solo, ar, água e biodiversidade. Boletim Informativo da Sociedade Brasileira de Ciência do Solo, Viçosa, v. 26, n. 4, p. 79, 2001. 
12. LUK, S. H.; ABRAHMNS, A. D.; PARSONS, A. J. Methodology: A Simple Rainfall Simulator and Trickle System for HydroGeomorphological Experiments. Physical Geography, v. 7, n. 4 p. 344-356, $1986 . \quad$ DOI: https://doi.org/10.1080/02723646.1986.10642303

13. MEYER, L.D.; HARMON, W.C. Interrill runoff and erosion: Effects of row-sideslope shape, rain energy, and rain intensity. Transactions of the ASAE, St Joseph, v.35, n.4, p.1199-1203, 1979. DOI: ISSN: 0001-2351.

14. OLIVEIRA JUNIOR, J. C; DIAS, H. C. Precipitação efetiva em fragmento secundário da Mata Atlântica. Revista Árvore, Viçosa, v. 29, n. 1, p. 09-15, 2005.ISSN 0100-6762. DOI: https://doi.org/10.1590/S0100-67622005000100002

15. OLIVEIRA, L.; COSTA, R.; SOUSA, F.; COSTA, A.; BRAGA, A. Precipitação efetiva e interceptação em Caxiuanã, na Amazônia Oriental. Acta Amazônica. Manaus, v. 38, n. 4, p. 723- 732, 2009 . ISSN 1809-4392. DOI: https://doi.org/10.1590/S0044-59672008000400016

16. OLIVEIRA, R.A. Distribuição de gotas por tamanho e perfil de precipitação de um aspersor fixo. Dissertação Mestrado. Viçosa, MG: UFV, 1991. 103p.

17. PANACHUKI, E.; BERTOL, I.; ALVES SOBRINHO, T.; OLIVEIRA, P.T.S.; RODRIGUES, D.B.B. Perdas de solo e de água e infiltração de água em Latossolo Vermelho sob sistemas de manejo. Revista Brasileira de Ciência do Solo, v.35, n.5, p.1777- 1785, 2011. DOI: https://doi.org/10.1590/S0100-06832011000500032

18. PINESE JÚNIOR, J. F.; CRUZ, L. M.; RODRIGUES, S. C. Monitoramento de erosão laminar em diferentes usos da terra, Uberlândia - MG. Sociedade \& Natureza, Uberlândia, v. 20, n. 2, p.157-175, dez. 2008.ISSN 1982-4513. DOI: https://doi.org/10.1590/S1982-45132008000200010.

19. SPOHR, R ; CORCINI, A ; PELLEGRIN, J. BONFANTI, J. SOTO, M. CARDOSO, T. Desenvolvimento e validação de um simulador de chuvas portátil. Revista Brasileira de Recursos Hídricos, v. 20, n. 2, p.411-417, 2015. ISSN $2318-0331$.

20. THOMAZ, E.; ANTONELI, V.. Erosão e degradação do solo em área cultivada com erva-mate (Ilex paraguariensis), Guarapuava - PR. Geociências - UNESP, v. 27, n. 1, p. 21-30, 2008.

21. TOSSELL, R. W; DICKINSON, W. T; RUDRA, R.P; WALL, G. J. A portable rainfall simulator. Canadian Agricultural Engineering, v.29, n.2, p.155-162, 1987.

22. TRICART, J. Ecodinâmica. Rio de Janeiro: FIBGE/SUPREN, 97p., 1977. ISBN: 24081-24500.

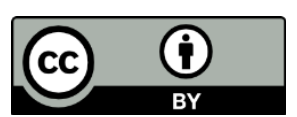

Esta obra está licenciada com uma Licença Creative Commons Atribuição 4.0 Internacional (http://creativecommons.org/licenses/by/4.0/) - CC BY. Esta licença permite que outros distribuam, remixem, adaptem e criem a partir do seu trabalho, mesmo para fins comerciais, desde que lhe atribuam o devido crédito pela criação original. 